\title{
Influence of Aluminium and Boron Orthophosphate on the Setting and the Resulting Structure of Alkali Silicate Binders for Refractory Application
}

\author{
Vanessa Hopp * (D, Ali Masoudi Alavi, Almuth Sax and Peter Quirmbach \\ Campus Koblenz, Faculty for Natural Science, University of Koblenz-Landau, 56070 Koblenz, Germany; \\ masoudi@uni-koblenz.de (A.M.A.); asax@uni-koblenz.de (A.S.); pquirmbach@uni-koblenz.de (P.Q.) \\ * Correspondence: vanmueller@uni-koblenz.de
}

Received: 27 November 2019; Accepted: 8 January 2020; Published: 9 January 2020

\begin{abstract}
Liquid alkali silicates (waterglasses) are used as chemical binders for a wide range of refractory applications, the setting of which can be initiated by the addition of phosphate hardeners. The duration of the setting process is of special interest for an economic lining with short aggregate downtimes. Therefore, in the present work, the influences of two different types of phosphate (aluminium orthophosphate and boron orthophosphate) on the hardening mechanisms of waterglasses are investigated. Time-dependent measurements by dynamic mechanical analysis (DMA) are carried out to observe the setting process. Structural information of the hardened amorphous samples is obtained by means of nuclear magnetic resonance (NMR) spectroscopy. It is shown that the use of different phosphates leads to differences in the setting rate, caused by different modes of network formation. The resultant silicate networks incorporate the aluminium or boron species but differ in the connectivity of those units. In addition, the distribution following the well-known $Q^{n}$ notation of the silicate units is directly influenced by the phosphate type.
\end{abstract}

Keywords: alkali silicates; phosphate hardener; binder; setting process; dynamic mechanical analysis; NMR spectroscopy

\section{Introduction}

Liquid alkali silicates, also known as waterglasses, have been widely used in many industrial applications, for example, in the production of detergents, paints, and adhesives. A large field of application has also been found in their use as chemical binders for different groups of materials, such as types of cement, grouts, and refractories [1,2]. Due to the increasing requirements for refractory materials, optimization of the binder components and of the binding process itself has gained more and more importance. In the case of waterglass binders, the duration of the setting process has become of particular interest, due to their use in cold-setting applications. Adjustment of the right setting duration allows an adequate processing time for lining and, at the same time, minimizes unnecessarily long downtimes of the aggregates. Therefore, in the present work, an extensive investigation was carried out on the setting process of chemically hardened waterglasses. The research focuses both on the influences of different factors (i.e., the chemistry of the chemical hardener, the hardener portion, and temperature) on the mechanisms of the setting process and the resulting network structures, which lead to the binding effect.

The term waterglasses refers to compounds of the formula $\mathrm{Me}_{2} \mathrm{O} \cdot \mathrm{nSiO}_{2}(\mathrm{Me}=$ alkali metal, mostly $\mathrm{Na}$ or K), which are soluble in water [2-4]. When dissolved in water, the alkali silicate sol contains dispersed colloid silicic acid, alkali ions, and monomer or oligomer silicate anions [5,6]. The variety of species depends on factors such as the $\mathrm{pH}$ value, the mole ratio of $\mathrm{SiO}_{2}$ to $\mathrm{Me}_{2} \mathrm{O}$, and the solid 
fraction [1,6]. The sol state is stabilized by an electrochemical double-layer at the surface of the silicate species [6-8]. Hardening of the liquid alkali silicates requires overcoming this sol state. The binding effect is based on the capability of the alkali silicates to form three-dimensional networks-the condensation to Si-O-Si bonds lead to the formation of macrostructures and, consequently, the sol converts to a gel. Further linking reactions cause setting to an amorphous glassy solid $[5,8,9]$. The structural changes of the silicate networks during their development from the sol state to the glassy solid are influenced by the setting mechanisms, which can be initiated physically (by the thermal removal of water) or chemically (due to reaction with $\mathrm{CO}_{2}$ or by addition of a hardener) $[1,3-6,10]$. The present work focuses on hardening by the addition of phosphates, due to their importance in industrial applications. However, the processes which take place during the hardening of alkali silicates by phosphates are still not known in detail. On the one hand, phosphates are an acid source, which reduces the electrochemical stabilization of the sol and, thus, force condensation reactions. On the other hand, phosphates act as network formers, due to their capability to form condensed and linked structures. Thus, phosphate structural units can be incorporated into the silicate network and, thus, contribute to the setting. In addition, the cations of the phosphate salts can also be integrated into the networks; for example, in the case of aluminium phosphates, it is known that $\mathrm{AlO}_{4^{-}}, \mathrm{AlO}_{5^{-}}$, and $\mathrm{AlO}_{6}$ units participate in network formation [3,6,11].

Several studies have shown the influences of different variations of phosphates on the hardening of waterglasses and the resulting influence on the structure and properties [2,11-13]. Concerning the phosphate structure, a correlation between the degradation of metaphosphates to ortho- and oligo-phosphates and the $\mathrm{pH}$ value has been found, where it was shown that a change in the $\mathrm{pH}$ directly influences the degree of condensation reactions and, thus, the cross-linking in the silicate network. At the same time, phosphate degradation causes a cation exchange between the silicate sol and the phosphate hardener, leading to changes in the electrochemical characteristics and, as a result, in the stabilization of the sol. Furthermore, it has been shown that the use of aluminium phosphates causes the formation of aluminosilicate networks, which present differing properties (in comparison to pure silicate ones). Even though a lot of work has been done to date, the influence of the phosphate-accompanying elements on the setting duration has not been investigated in detail. Therefore, the present work focuses on the role of those elements on both the setting mechanism of alkali silicates and on the resulting structure of the networks. For this purpose, the effects of aluminium and boron compounds from an orthophosphate source $\left(\mathrm{AlPO}_{4}\right.$ and $\mathrm{BPO}_{4}$, respectively) were studied.

\section{Materials and Methods}

\subsection{Materials}

The influences of two different orthophosphates on the setting behaviour of liquid alkali silicates and the resulting structure were determined. First, an aluminium orthophosphate powder $\left(\mathrm{AlPO}_{4}\right.$, LITHOPIX P26, berlinite-type; Zschimmer \& Schwarz, Milledgeville, GA, USA) was used, as the group of aluminium phosphates has been widely used as hardeners for alkali silicates in industrial refractory applications. The orthophosphate form was chosen to avoid setting effects due to degradation. In addition, all experiments were conducted using a boron orthophosphate powder $\left(\mathrm{BPO}_{4}, \mathrm{FFB761}\right.$; Budenheim, Germany). Boron and aluminium are in the same group of the periodic table of the elements and show both similarities and differences in their chemical behavior. For this reason, their comparison offers interesting insights into the relationships of the chosen hardener and the alkali silicate used in the setting process.

Mixtures of various proportions (10, 20, and 30 mass $\%$ ) of these orthophosphates and a sodium waterglass (N250 by Askania) with a molar ratio $\mathrm{SiO}_{2} / \mathrm{Na}_{2} \mathrm{O}$ of 2.5 and a solid content of about 42 mass $\%$ were prepared at ambient temperatures $\mathrm{T}_{\mathrm{A}}=25,35$, and $45^{\circ} \mathrm{C}$. To avoid agglomeration, the powder phosphate was added to the waterglass sol through a sieve. The mixture was stirred manually for three minutes for homogenisation. The prepared pasty samples were directly investigated 
by time-dependent measurements at $\mathrm{T}_{\mathrm{A}}=25,35$, and $45^{\circ} \mathrm{C}$ by means of dynamic mechanical analysis (DMA). For the solid-state nuclear magnetic resonance spectroscopy (NMR) magic angle spinning (MAS) experiments, only mixtures with 20 mass $\%$ hardener added, and which were prepared at $\mathrm{T}_{\mathrm{A}}=25^{\circ} \mathrm{C}$ were investigated, due to the very long duration of the measurements. The mixtures were dried for 48 hours $\left(\mathrm{T}_{\mathrm{A}}=25^{\circ} \mathrm{C}, 70 \%\right.$ relative humidity) and then ground manually to a fine powder.

\subsection{Methods}

In order to characterize the interactions between the liquid alkali silicates and phosphate hardeners during the setting process, waterglass-phosphate mixes were investigated by means of dynamic mechanical analysis (DMA). In addition, structural information was obtained by nuclear magnetic resonance spectroscopy (NMR) experiments using thoroughly hardened samples.

\subsubsection{Dynamic Mechanical Analysis}

Dynamic mechanical analysis is used to observe a material's viscoelastic behavior under an oscillating load. The viscoelastic properties are composed of both an elastic part and a plastic part, which describe the stored or lost energy in the material during the application of mechanical force. The elastic part (stored energy) is expressed as the so-called storage modulus $\mathrm{E}^{\mathrm{I}}$, whereas the loss modulus $\mathrm{E}^{\mathrm{II}}$ describes the plastic part (lost energy). The ratio between $\mathrm{E}^{\mathrm{II}}$ and $\mathrm{E}^{\mathrm{I}}$ is defined as the loss factor $\tan \delta$ [14]. The DMA determines those variables by time-dependent measurements and was, thus, determined as a suitable method for tracing the hardening processes of alkali silicates, as has already been shown in preceding work [15].

For the present investigation, the time-dependent course of the storage modulus $\mathrm{E}^{\mathrm{I}}$ was observed, as it can directly show the setting process by an increase in the material's stiffness. In addition, characteristic stages of setting were defined by determining the gel points and the glass points. The gel point was identified as the point in time when the frequency dependence of $\tan \delta$ disappeared [15]. The glass point was determined as the maximum in the loss modulus $\mathrm{E}^{\mathrm{II}}$ at a frequency of $1 \mathrm{~Hz}$ [16].

For both the examination of the temporal progression in storage modulus and the determination of the gel and glass points, stress-controlled measurements with cyclic frequency sweeps (frequency window between $1-25 \mathrm{~Hz}$ ) were conducted using a DMA $242{ }^{\circ} \mathrm{C}$ (Netzsch). The frequencies were selected with regard to the required measuring temperatures. Even at low temperatures $\left(\mathrm{T}=35^{\circ} \mathrm{C}\right.$ and $\left.\mathrm{T}=45^{\circ} \mathrm{C}\right)$, Kim et al., [17] found a shift of $\tan \delta$ in the low-frequency range $(\omega<8 \mathrm{rad} / \mathrm{s})$ induced by thermal fluctuation. This shift hinders the determination of distinct time values for the gel point. As the present investigations were carried out at temperatures of $\mathrm{T}_{\mathrm{A}}=25,35$, and $45^{\circ} \mathrm{C}$, higher frequencies were chosen to avoid such effects. A temperature chamber enclosing the samples was used to ensure constant temperatures. An overview of the further measuring parameters is given in Table 1.

Table 1. Measuring parameters of dynamic mechanical analysis.

\begin{tabular}{cc}
\hline DMA Parameter & Value \\
\hline Instrument & DMA 242 C, Netzsch \\
Amplitude & $50 \mu \mathrm{m}$ \\
Maximum dynamic force & $7 \mathrm{~N}$ \\
Additional constant portion of the static force & $0 \mathrm{~N}$ \\
Proportional factor & 0 \\
Frequencies & $1,5,10,16.666,20,25 \mathrm{~Hz}$ \\
\hline
\end{tabular}

For the measurement of the pasty samples, a crucible with spherical feeler stamp was used. With the stamp, it was not possible to determine the absolute values of the mechanical parameters. Therefore, the maximum achieved storage or loss modulus in every test series was set to $100 \%$. The DMA crucible was filled with the waterglass-phosphate mix to a height of $h=11 \mathrm{~mm}$ and the feeler stamp was immersed completely into the pasty material. To ensure accurate time-dependent measurements, 
the preparation procedure was exactly determined with regard to its duration. Therefore, the DMA measurements were always started five minutes after the beginning of the preparation (i.e., the addition of the hardener to the waterglass) to ensure an adequate and constant time slot for mixing and integration of the samples into the DMA holder. This time was added to the pure measuring time of the DMA experiment.

\subsubsection{Nuclear Magnetic Resonance Spectroscopy}

For structural analysis of the predominant $x$-ray amorphous portion of the alkali silicate-phosphate mixes, solid-state magic angle spinning nuclear magnetic resonance spectroscopy (NMR MAS) studies of powder samples from the dried mixes were performed. The experiments were carried out with a Jeol $500 \mathrm{MHz}$ spectrometer ECZR using a probe head equipped with two channels and $3.2 \mathrm{~mm}$ rotators. The magnetic field was $\mathrm{E}=11.75 \mathrm{~T}$ and the temperature was $\mathrm{T}=21^{\circ} \mathrm{C}$. All spectra were collected using single pulse measurements of ${ }^{29} \mathrm{Si},{ }^{11} \mathrm{~B}$, and ${ }^{27} \mathrm{Al}$ under magic angle spinning (MAS) conditions. The MAS spinning frequencies were $8 \mathrm{kHz}$ for ${ }^{29} \mathrm{Si}$ and ${ }^{11} \mathrm{~B}$, and $12 \mathrm{kHz}$ for ${ }^{27} \mathrm{Al}$. The ${ }^{29} \mathrm{Si}$ spectra were collected at a resonance frequency of $99.4 \mathrm{MHz}$, the ${ }^{27} \mathrm{Al}$ spectra at $130.3 \mathrm{MHz}$, and the ${ }^{11} \mathrm{~B}$ spectra at a resonance frequency of $160.4 \mathrm{MHz}$.

\section{Results}

\subsection{Dynamic Mechanical Analysis}

The setting process of the alkali silicate-phosphate mixes, as represented by the time-dependent course of the storage modulus $\mathrm{E}^{\mathrm{I}}$ (elastic part), is exemplified by measurements at $\mathrm{T}_{\mathrm{A}}=25^{\circ} \mathrm{C}$ in Figure 1 $\left(\mathrm{AlPO}_{4}\right.$ hardener) and Figure $2\left(\mathrm{BPO}_{4}\right.$ hardener). The $10 \mathrm{~Hz}$ curves of the storage modulus are shown. A measurement of pure waterglass without any hardener added was used as a reference.

The $\mathrm{E}^{\mathrm{I}}$ curves of the samples which were hardened using 20 and 30 mass $\% \mathrm{AlPO}_{4}$ (Figure 1) showed a sigmoid development, which is typical for setting processes. After only a slight increase in storage modulus at the beginning, a much stronger incline followed, which led to a limit in the storage modulus where it became almost constant. Significant differences can be seen in the results of the sample containing 10 mass\% hardener-the storage modulus increased very slowly and only reached small values after the measurement time of $t=4$ hours. Therefore, this curve only slightly exceeded the reference curve. In both cases, the setting of the samples was incomplete.

The shown development in storage modulus almost conformed with the behaviour of samples hardened at higher temperatures $\left(\mathrm{T}_{\mathrm{A}}=35^{\circ} \mathrm{C}\right.$, Figure $\mathrm{S} 1 ; \mathrm{T}_{\mathrm{A}}=45^{\circ} \mathrm{C}$, Figure S2).

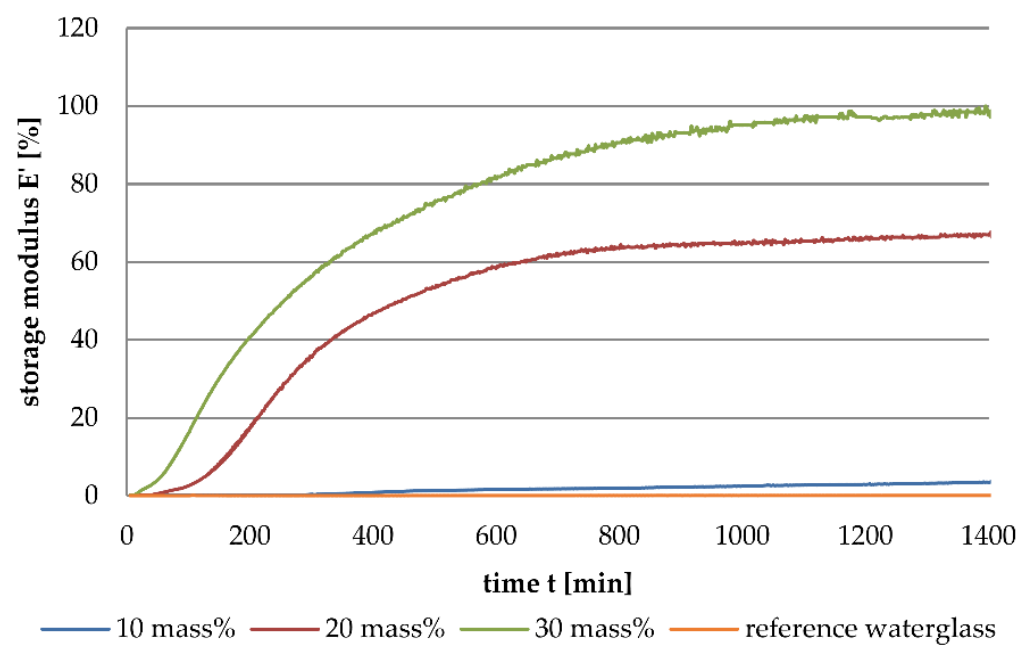

Figure 1. DMA measurements of the waterglass samples with different added content of $\mathrm{AlPO}_{4}$ hardener at $\mathrm{T}_{\mathrm{A}}=25^{\circ} \mathrm{C}$. The reference is a waterglass sample without any hardener added. 
The setting of samples with the addition of boron phosphate also led to a sigmoid curve progression (Figure 2). However, samples with an addition of 20 and 30 mass $\% \mathrm{BPO}_{4}$ showed a strong decrease of storage modulus in the course of the setting process (30 mass \%: after about $83 \mathrm{~min} ; 20 \mathrm{mass} \%$ : after about $665 \mathrm{~min}$ ) until the complete interruption of the measurement. Furthermore, this loss of signal for the samples with 20 and 30 mass $\% \mathrm{BPO}_{4}$ addition can be observed in the measurements at $\mathrm{T}_{\mathrm{A}}=35^{\circ} \mathrm{C}$ (Figure S3) and $\mathrm{T}_{\mathrm{A}}=45^{\circ} \mathrm{C}$ (Figure S4).

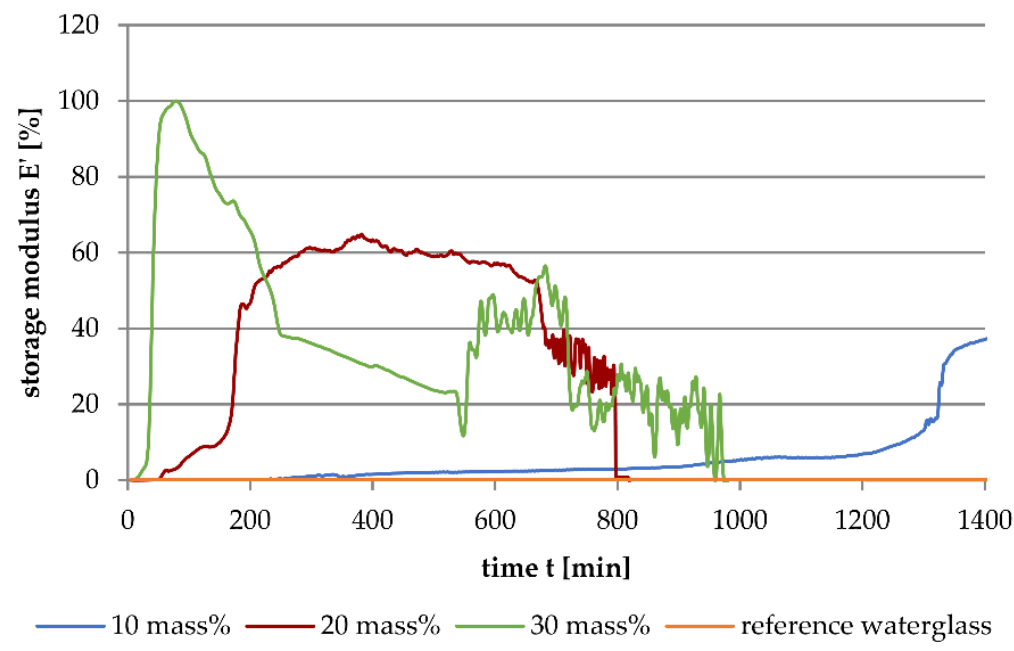

Figure 2. DMA measurements of the waterglass samples with different added content of $\mathrm{BPO}_{4}$ hardener at $\mathrm{T}_{\mathrm{A}}=25^{\circ} \mathrm{C}$. The reference is a waterglass sample without any hardener added.

The gel and glass points determined by the help of the DMA measurements (triple determination) were used to build up TTT (Time-Temperature-Transformation) diagrams, as shown in Figure 3 (values are given in Tables 2 and 3, for more details about their determination see Figures S5-S20). These diagrams illustrate the setting states (sol, gel, and glass) as a function of setting time and temperature for all quantities of $\mathrm{AlPO}_{4}$ and $\mathrm{BPO}_{4}$ hardener. Both gel point and glass point shifted to lower time values with increasing temperature or increasing hardener addition. It is worth noting that the gel points of both hardeners were relatively close together, whereas the glass points strongly differed. The solid-state was always reached earlier by $\mathrm{BPO}_{4}$ addition, followed by $\mathrm{AlPO}_{4}$ addition, even though the gel points of the alkali silicate- $\mathrm{BPO}_{4}$ mixes occurred mostly later than the gel points of the samples containing $\mathrm{AlPO}_{4}$.

Table 2. Glass and gel points for the waterglass samples with added $\mathrm{AlPO}_{4}$.

\begin{tabular}{ccccccc}
\hline \multirow{2}{*}{$\mathbf{T}_{\mathbf{A}}$} & \multicolumn{2}{c}{$\mathbf{1 0}$ mass\% } & \multicolumn{2}{c}{$\mathbf{2 0}$ mass $\%$} & \multicolumn{2}{c}{$\mathbf{3 0 \text { mass } \%}$} \\
\cline { 2 - 6 } & Gel Point & Glass Point & Gel Point & Glass Point & Gel Point & Glass Point \\
\hline $25{ }^{\circ} \mathrm{C}$ & 290 & & 42.5 & 258.8 & 14.75 & 173.3 \\
$35^{\circ} \mathrm{C}$ & 77.8 & & 27 & 153 & 11 & 146.4 \\
$45^{\circ} \mathrm{C}$ & 39.5 & & 23 & 95.5 & 9.2 & 57.3 \\
\hline
\end{tabular}

Table 3. Glass and gel points for the waterglass samples with added $\mathrm{BPO}_{4}$.

\begin{tabular}{ccccccc}
\hline \multirow{2}{*}{$\mathbf{T}_{\mathbf{A}}$} & \multicolumn{2}{c}{$\mathbf{1 0}$ mass $\%$} & \multicolumn{2}{c}{$\mathbf{2 0}$ mass $\%$} & \multicolumn{2}{c}{$\mathbf{3 0 \text { mass } \%}$} \\
\cline { 2 - 6 } & Gel Point & Glass Point & Gel Point & Glass Point & Gel Point & Glass Point \\
\hline $25{ }^{\circ} \mathrm{C}$ & 295 & & 52.4 & 189 & 15.7 & 99.1 \\
$35^{\circ} \mathrm{C}$ & 222.5 & 893.2 & 32.4 & 55.8 & 10.6 & 35.8 \\
$45{ }^{\circ} \mathrm{C}$ & 71 & 391 & 17.5 & 31.6 & 9.9 & 22.4 \\
\hline
\end{tabular}



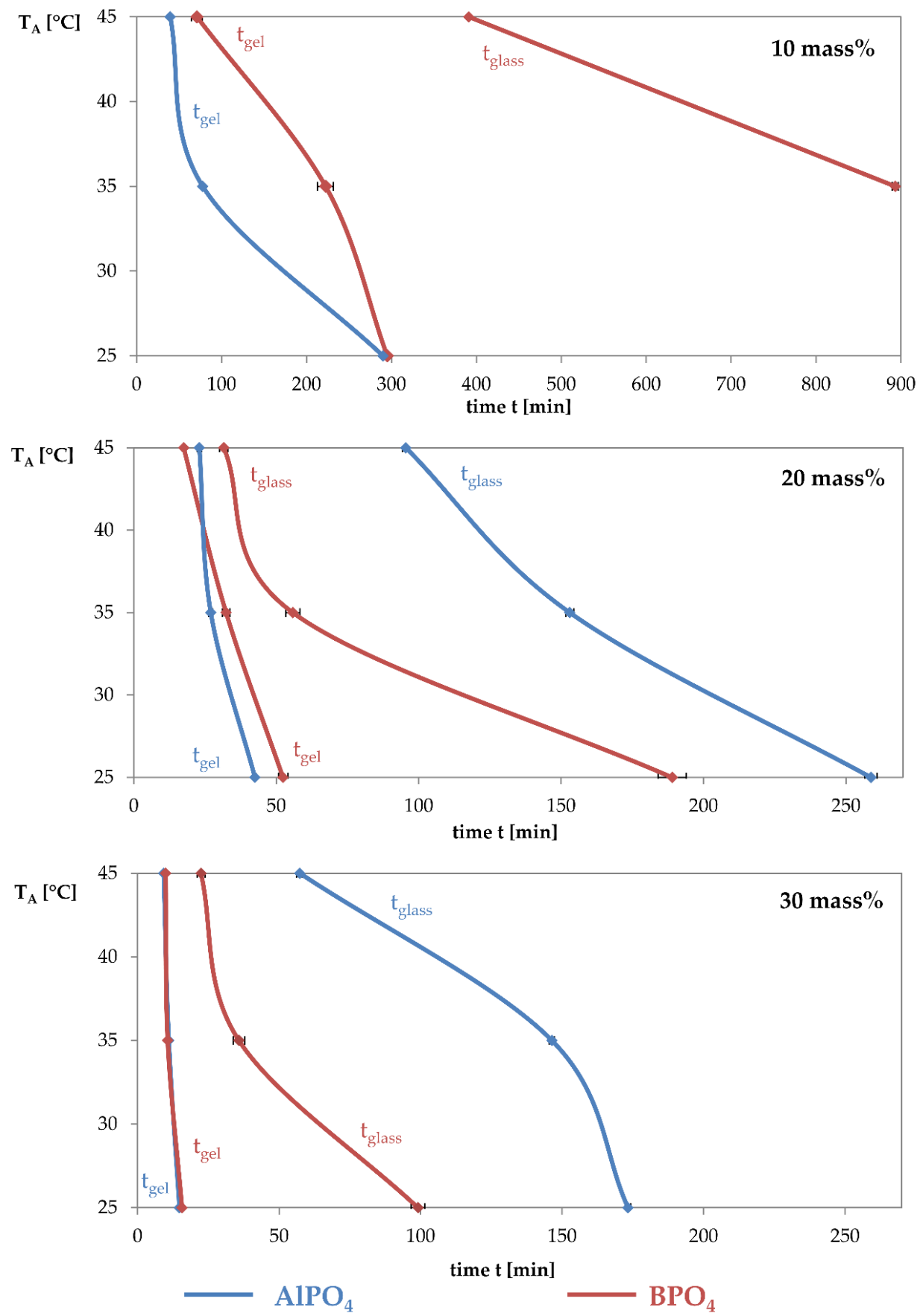

Figure 3. Time-temperature-transformation diagrams of the phosphate-waterglass mixes.

\subsection{Nuclear Magnetic Resonance Spectroscopy}

The ${ }^{29} \mathrm{Si}$ MAS NMR spectra of the phosphate-hardened waterglasses show a number of broad signals typical of solid-state NMR (Figure 4, (a) $\mathrm{AlPO}_{4}$ hardener; (b) $\mathrm{BPO}_{4}$ hardener). The small natural abundance of the NMR active ${ }^{29} \mathrm{Si}$ isotope and its small gyromagnetic ratio contribute to the broadening of the signals. Both spectra have one strongly asymmetric peak, indicating an overlap of poorly resolved peaks in the range of $60 \mathrm{ppm}$ up to about $130 \mathrm{ppm}$, which is typical for silicate glasses. Deconvolution of the signal offers the possibility for a more accurate description of the signal and, therefore, gives information about the $\mathrm{Q}^{\mathrm{n}}$ notation. To that end, the curve progression of the cumulative signal was reproduced by a suitable combination of single curves with both Lorentzian and Gaussian portions. In the figures, the original spectrum is painted in dark red. The suggested single curves are 
blue and the estimated resulting overall signal of the single curves is magenta. The difference between the original and the estimated spectra is given in red.

The ${ }^{29} \mathrm{Si}$ MAS NMR spectra of the samples with $\mathrm{AlPO}_{4}$ hardeners can be described by four single signals at $-78,-91,-101$, and $-111 \mathrm{ppm}$. The chemical shift regions for the $\mathrm{Q}^{0}$ to $\mathrm{Q}^{4}$ units in the silicates are indicated by the black bars. The signal at $-78 \mathrm{ppm}$ was assigned to type $\mathrm{Q}^{1}$. To what extent $\mathrm{Q}^{0}$ contributed to this signal could not be estimated, due to the low intensity and the width of the peak. The three other signals were assigned to type $\mathrm{Q}^{2}, \mathrm{Q}^{3}$, and $\mathrm{Q}^{4}$ silicate species.

Even after hardening with $\mathrm{BPO}_{4}$, the signal in the ${ }^{29} \mathrm{Si}$ MAS NMR spectra was deconvolved into four single curves, which can be attributed to the typical $Q^{n}$ ranges. Again, differentiation between $Q^{0}$ and $\mathrm{Q}^{1}$ was not possible; however, the signal in this range was much more distinct, in comparison to the appropriate signal in the case of $\mathrm{AlPO}_{4}$ hardening. Thus, it can be summarized that the $\mathrm{Q}^{\mathrm{n}}$ notation for $\mathrm{BPO}_{4}$ hardening was shifted towards lower $\mathrm{n}$ values.

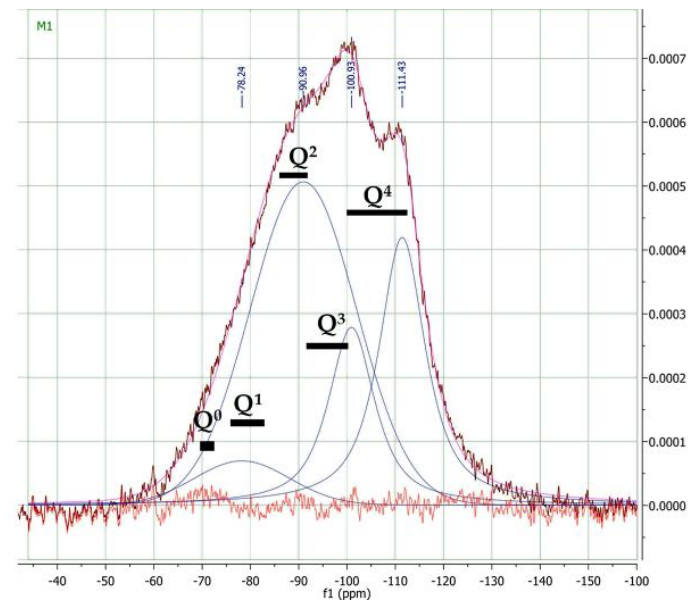

(a)

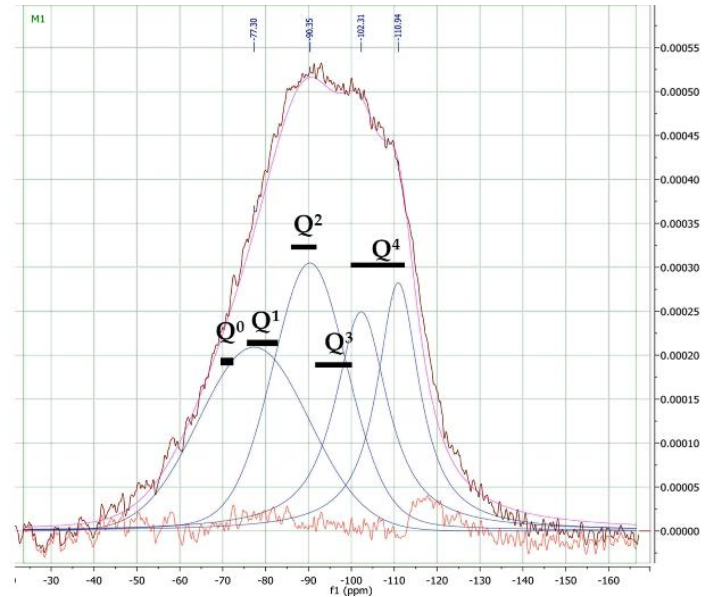

(b)

Figure 4. ${ }^{29} \mathrm{Si}$ MAS spectra of dried waterglass samples and deconvolution with $\mathrm{Q}^{\mathrm{n}}$ attribution, MAS spinning frequency: $8 \mathrm{kHz}$; resonance frequency: $99.4 \mathrm{MHz}$; (a) hardening with $\mathrm{AlPO}_{4}, 20,000$ scans; (b) hardening with $\mathrm{BPO}_{4}, 12416$ scans.

The spectrum of the ${ }^{27} \mathrm{Al}$ MAS NMR experiment is shown in Figure 5a. It contains two intense peaks with maxima at 74 and $5 \mathrm{ppm}$ and two small overlapping peaks at about 40 and $45 \mathrm{ppm}$. The first signal at $74 \mathrm{ppm}$ was assigned to a tetrahedrally coordinated aluminium species $\mathrm{AlO}_{4}$ and an octahedral $\mathrm{AlO}_{6}$ species was found for the peak at 5 ppm [18]. Both signals tended to shift towards higher ppm values, compared to the ranges that are usually assumed for those species $\left(\mathrm{AlO}_{4}: 50-80 \mathrm{ppm}\right.$ and $\mathrm{AlO}_{6}$ : $-10-10 \mathrm{ppm}$ [19]). This hindered the classification of the two small peaks. The one at $40 \mathrm{ppm}$ touches the border area of the $\mathrm{AlO}_{5}$ co-ordination (30-40 ppm [19]). However, the occurrence of tetrahedral aluminium, which is linked with phosphor by an oxygen bridge, has also been correlated to that range of chemical shift [20]. Hence, for this peak and for the second small peak at $45 \mathrm{ppm}$, differentiation between $\mathrm{AlO}_{5}$ and $\mathrm{AlO}_{6}$ species was not reasonable.

The ${ }^{11} \mathrm{~B}$ MAS NMR spectrum of the waterglasses with $\mathrm{BPO}_{4}$ addition in Figure $5 \mathrm{~b}$ shows two signals. On one hand, an intense and well-defined peak with a maximum at -2.9 ppm can be seen; on the other hand, a very broad and poor resolved signal can be seen in the range of 15 to $-5 \mathrm{ppm}$. As stated by Gan et al., who found those chemical shifts for boron species in silicate glasses with both alkaline and phosphorous network components, the two peaks can be assigned to boron species with different co-ordinations [18]. The first one (at $-2.9 \mathrm{ppm}$ ) was attributed to tetrahedral boron $\mathrm{BO}_{4}$ species and the broadened signal (with centre at about $9 \mathrm{ppm}$ ) could be correlated with the trigonal $\mathrm{BO}_{3}$ form. 


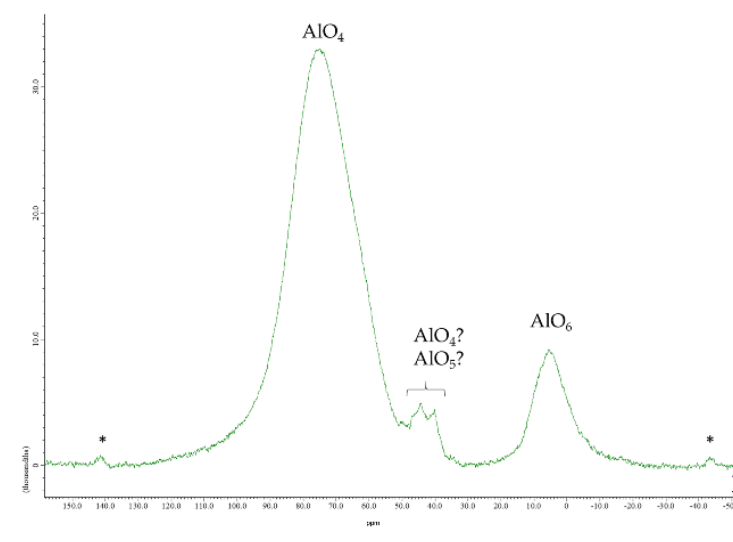

(a)

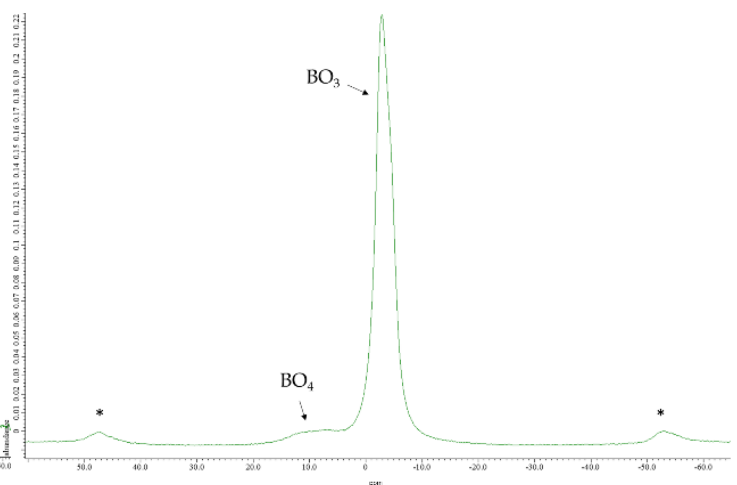

(b)

Figure 5. Magic angle spinning nuclear magnetic resonance spectroscopy (NMR MAS) spectra of waterglass containing phosphate hardener; spinning sidebands are marked with *; (a) ${ }^{27} \mathrm{Al}$ MAS spectrum of waterglass containing $\mathrm{AlPO}_{4}$ hardener, MAS spinning frequency: $12 \mathrm{kHz}$, resonance frequency: $130.3 \mathrm{MHz}, 250$ scans; (b) ${ }^{11} \mathrm{~B}$ MAS spectrum of waterglass containing $\mathrm{BPO}_{4}$ hardener, MAS spinning frequency: $8 \mathrm{kHz}$; resonance frequency: $160.4 \mathrm{MHz}, 444$ scans.

\section{Discussion}

When comparing the results of the DMA measurements of the alkali silicate-phosphate mixes with either $\mathrm{AlPO}_{4}$ or $\mathrm{BPO}_{4}$ addition, it can be seen that the gel points only slightly differed; however, significant deviations were found regarding the glass transition. The use of the $\mathrm{BPO}_{4}$ (instead of $\mathrm{AlPO}_{4}$ ) hardener always led to earlier time values for the glass point.

The combined examination of the gel points and the time-dependent course of the storage modulus in Figure 6 indicates the reasons for this behaviour. It can be clearly seen that the differences in setting behaviour between the two types of hardener occurred first after reaching the gel point. In contrast, the behaviour in the first stage before the gel point could be mainly described by the temperature and the hardener quantity and, thus, was directly dependent on the liquid-to-solid relationship in the sol.

Hardening with $\mathrm{BPO}_{4}$ led to a fast and strong increase in storage modulus immediately after reaching the gel point. The use of $\mathrm{AlPO}_{4}$ resulted in a more moderate increase in the storage modulus $\mathrm{E}^{\mathrm{I}}$-however, it led to higher limiting values.

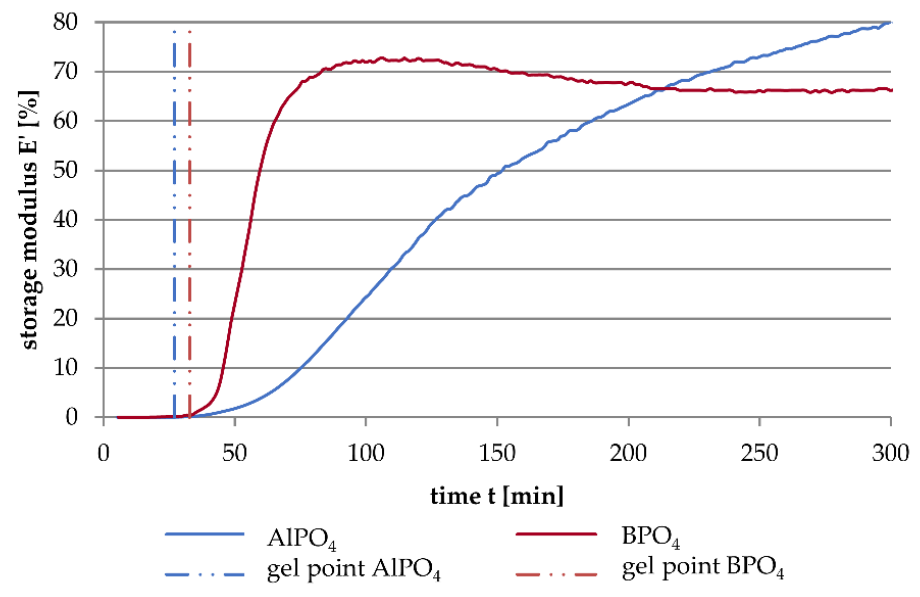

Figure 6. Differences in the development of the storage modulus of the waterglass samples with added content of $\mathrm{AlPO}_{4}$ and $\mathrm{BPO}_{4},\left(20\right.$ mass $\%$ hardener, $\left.\mathrm{T}_{\mathrm{A}}=35{ }^{\circ} \mathrm{C}\right)$. The gel points of the samples are indicated by the dashed lines. 
Amongst others, the rheological investigations of sol-gel systems of Bleuzen et al., correlated the amount of the maximal reached storage modulus with the density of linkage in the resultant network [21]. Even in the case of the present investigation, the findings of the NMR experiments indicated differences in the linking status within the silicate network. Both the information concerning the $\mathrm{Q}^{\mathrm{n}}$ notation from the ${ }^{29} \mathrm{Si}$ MAS NMR experiments and the results regarding the differences in the co-ordination of aluminium and boron species showed that hardening by $\mathrm{AlPO}_{4}$ addition led to glassy solids with a higher linkage density than that in the case of hardening with $\mathrm{BPO}_{4}$. This was expressed, amongst other things, in the lower stability of the $\mathrm{BPO}_{4}$ hardened samples; in which the mechanical strain of the feeler stamp led to cracks and, subsequently, to a loss of signal during DMA measurements.

It is well-known that differences in the setting process of waterglasses, which are based on the electrochemical status and the $\mathrm{pH}$ value, result in the formation of networks with variable linking densities. This model of so-called slow and fast aggregation has been described by Wijnen et al., [22]. Fast aggregation is diffusion-limited and leads to a fast-growing but only rarely linked network, due to further network-forming reactions in the periphery of the pre-existing network structure. In contrast, a highly linked but slowly growing network is formed in case of the slow, reaction-limited aggregation, as network-forming reactions occur within the network, where cross-linking already exists. The resulting potential at the surface of the silicate particles is responsible for these mechanisms, according to the theory of Derjaguin, Landau, Verwey and Overbeek (DLVO theory). This electrochemical potential significantly determines the success of network-forming condensation reactions.

Due to the complexity of the whole setting process of waterglass-phosphate systems, the mechanism cannot be assumed to be only diffusion- or only reaction-limited. Nevertheless, the present results indicate network formation corresponding to the described model for the hardening of waterglasses with $\mathrm{AlPO}_{4}$ and $\mathrm{BPO}_{4}$. Thus, a relieved spatial approach of the participating components (both silicate and hardener species) is recommended for the hardening process with $\mathrm{BPO}_{4}$, resulting in a high chance for condensation reactions. The consequence is a fast-growing, wide network over the whole waterglass volume (network-forming reactions in the periphery), leading to a fast increase in the material's stiffness and, thereby, in storage modulus.

When hardening with $\mathrm{AlPO}_{4}$, the barrier for the formation of new chemical bonds to the network is higher, such that (according to the described model) network sub-structures with high densities result from network-forming reactions within the network. The developing highly linked units are still surrounded by a big part of liquid waterglass, which leads to a slower increase in storage modulus, in comparison to $\mathrm{BPO}_{4}$ hardening.

This also provides an explanation for another effect that occurred during DMA measurement. The slope of the storage modulus curve increased more and more over the setting progress of the samples containing the $\mathrm{AlPO}_{4}$ hardener. The more chemical bonds and, thereby, cross-links that were formed during the setting process, the denser the growing network became. For this reason, the chance for a spatial approach of the involved components rose and the hardening accelerated.

\section{Conclusions}

The influences of aluminium and boron orthophosphate on the setting time and the resulting amorphous structure of liquid alkali silicates were investigated by means of dynamic mechanical analysis and nuclear magnetic resonance spectroscopy. It was shown that the different phosphates led to differences in the hardening mechanism:

- The addition of aluminium orthophosphate $\left(\mathrm{AlPO}_{4}\right)$ to liquid alkali silicates results in a lower increase of the storage modulus when compared to the addition of boron orthophosphate.

- The different rates in storage modulus development correlate with the linking density and the locations of network-forming condensation reactions.

- Boron orthophosphate $\left(\mathrm{BPO}_{4}\right)$ addition leads to a fast-growing but rarely linked network, due to network-forming reactions in the periphery of the network. 
- Hardening with $\mathrm{AlPO}_{4}$ causes network-forming reactions within the network, leading to the formation of highly linked sub-structures surrounded by liquid waterglass. The consequence is a significantly slower increase in storage modulus.

Supplementary Materials: The following are available online at http://www.mdpi.com/2571-6131/3/1/1/s1, Figure S1: DMA measurements of the waterglass samples with different added content of $\mathrm{AlPO}_{4}$ hardener at $\mathrm{T}_{\mathrm{A}}=35^{\circ} \mathrm{C}$. The reference is a waterglass sample without any hardener added. Figure S2: DMA measurements of the waterglass samples with different added content of $\mathrm{AlPO}_{4}$ hardener at $\mathrm{T}_{\mathrm{A}}=45^{\circ} \mathrm{C}$. The reference is a waterglass sample without any hardener added. Figure S3: DMA measurements of the waterglass samples with different added content of $\mathrm{BPO}_{4}$ hardener at $\mathrm{T}_{\mathrm{A}}=35^{\circ} \mathrm{C}$. The reference is a waterglass sample without any hardener added. Figure S4: DMA measurements of the waterglass samples with different added content of $\mathrm{BPO}_{4}$ hardener at $\mathrm{T}_{\mathrm{A}}$ $=45^{\circ} \mathrm{C}$. The reference is a waterglass sample without any hardener added. Gel point determination: Point of frequency-independence of the $\tan \delta, \mathrm{T}_{\mathrm{A}}=25^{\circ} \mathrm{C}$ : frequency-independence of the $\tan \delta$ in detail, curing time is corrected with regard to the time for preparation of the measurement (=5 min). Figure S5: 10 mass $\%, \mathrm{~T}_{\mathrm{A}}=25^{\circ} \mathrm{C}$. Figure S6: 20 mass $\%, \mathrm{~T}_{\mathrm{A}}=25^{\circ} \mathrm{C}$. Figure S7: 30 mass $\%, \mathrm{~T}_{\mathrm{A}}=25^{\circ} \mathrm{C} . \mathrm{T}_{\mathrm{A}}=35^{\circ} \mathrm{C}$ and $\mathrm{T}_{\mathrm{A}}=45^{\circ} \mathrm{C}$ : Overview of frequency-independence of the tan $\delta$ directly from the software (that means without time correction). Figure S8: AlPO4, $\mathrm{T}_{\mathrm{A}}=35^{\circ} \mathrm{C}$. Figure S9: AlPO4, $\mathrm{T}_{\mathrm{A}}=45^{\circ} \mathrm{C}$. Glass point determination: Maximum of the Loss modulus $\mathrm{E}^{\prime \prime}(1 \mathrm{~Hz}) \cdot \mathrm{T}_{\mathrm{A}}=25^{\circ} \mathrm{C}$ : Glass point determination in detail, curing time is corrected with regard to the time for preparation of the measurement ( $=5 \mathrm{~min})$. Figure S10: 10 mass $\%, \mathrm{~T}_{\mathrm{A}}=25^{\circ} \mathrm{C}$. Figure S11: 20 mass $\%, \mathrm{~T}_{\mathrm{A}}=25{ }^{\circ} \mathrm{C}$. Figure S12: 30 mass $\%, \mathrm{~T}_{\mathrm{A}}=25^{\circ} \mathrm{C} \cdot \mathrm{T}_{\mathrm{A}}=35^{\circ} \mathrm{C}$ and $\mathrm{T}_{\mathrm{A}}=45^{\circ} \mathrm{C}$ : Overview of the glass point determination directly from the software (that means without time correction). Figure S13: AlPO4, $\mathrm{T}_{\mathrm{A}}=35^{\circ} \mathrm{C}$. Figure S14: AlPO4, $\mathrm{T}_{\mathrm{A}}=45^{\circ} \mathrm{C}$. BPO4 hardener a) Gel point determination: Point of frequency-independence of the tan $\delta$, Overview directly from the software (that means without time correction). Figure S15: $\mathrm{BPO} 4, \mathrm{~T}_{\mathrm{A}}=25^{\circ} \mathrm{C}$. Figure S16: $\mathrm{BPO} 4$, $\mathrm{T}_{\mathrm{A}}=35^{\circ} \mathrm{C}$. Figure S17: $\mathrm{BPO} 4, \mathrm{~T}_{\mathrm{A}}=45^{\circ} \mathrm{C}$. b) Glass point determination: Maximum of the Loss modulus E" $(1 \mathrm{~Hz})$. Figure S18: $\mathrm{BPO} 4, \mathrm{~T}_{\mathrm{A}}=25^{\circ} \mathrm{C}$. Figure S19: $\mathrm{BPO} 4, \mathrm{~T}_{\mathrm{A}}=35^{\circ} \mathrm{C}$. Figure S20: $\mathrm{BPO} 4, \mathrm{~T}_{\mathrm{A}}=45^{\circ} \mathrm{C}$.

Author Contributions: Conceptualization, V.H., A.S., and P.Q.; Formal analysis, V.H. and A.M.A.; Investigation, V.H. and A.M.A.; Methodology, V.H.; Project administration, A.S. and P.Q.; Supervision, P.Q.; Validation, V.H. and A.M.A.; Visualization, V.H.; Writing original draft, V.H.; Writing review \& editing, A.S. All authors have read and agreed to the published version of the manuscript.

Funding: This research received no external funding.

Conflicts of Interest: The authors declare no conflict of interest.

\section{References}

1. Wenda, R.W. Die aktuelle Wochenschau der GDCh. Available online: http://archiv.aktuelle-wochenschau.de/ 2011/w36/woche36.html (accessed on 9 January 2020).

2. Zellmann, H.D. Metaphosphat-modifizierte Silikatbinder als Basis Säurebeständiger Beschichtungsmaterialien. Ph.D. Thesis, Bauhaus University Weimar, Weimar, Germany, 19 September 2008.

3. Giskow, R. Waterglass and Phosphate-A System for Alchemists? Ceram. forum Int. 2005, 82, 22-26.

4. Pavlovský, J.; Thomas, B.; Brendler, E.; Polzin, H.; Tilch, W.; Skuta, R.; Jelínek, P. Wasserglasgebundene Formstoffe. Untersuchungen zum Einfluss des Silikatmoduls und der Verdünnung auf die Struktur und die Festigkeitseigenschaften von Wasserglaslösungen und zur Kinetik des Härtungsprozesses. Giess.-Prax. 2005, 3, 82-88.

5. Roggendorf, H. Strukturmodelle von Wassergläsern? In Referate und Vorträge der 83 Glastech; Tagung der DGG: Amberg, Germany, 2009.

6. Schuch, K. Steuerung des Aggregationsprozesses in wässrigen Alkalisilikatsolen durch spezielle Gelinitiatoren und moderate Wärmebehandlung zum Aufbau einer stabilen Silikatbeschichtung. Ph.D. Thesis, Bauhaus University Weimar, Weimar, Germany, 21 November 2015.

7. Roggendorf, H.; Böschel, D. Hydrous sodium silicate glasses obtained by drying sodium silicate solutions. Glass Sci. Technol. 2002, 75, 103-111.

8. Roggendorf, H.; Wolter, H.; Trempler, J.; Runge, J.; Busse, K.; Adhikari, R.; Kressler, J.; Michler, G.H. Inorganic colloidal glasses-relations between preparation and structure. Eur. J. Glass Sci. Tech. B. Phys. Chem. Glasses 2005, 46, 439-443.

9. Parr, C.; Auvray, J.M.; Szepizdyn, M.; Wöhrmeyer, C.; Zetterstrom, C. A Review of Bond Systems for Monolithic Castable Refractories. Refract. worldforum 2015, 7, 63-70.

10. Polzin, H. Die Anwendung kaltselbsthärtender anorganischer Bindersysteme. Giess.-Prax. 2010, 9, $282-287$.

11. Staffel, T.; Wahl, F.; Weber, S.; Glaum, L.; Glaum, R. Kälte und Feuchte—na und? Polym. Alum. als Wasserglashärter 2002, 108, 103-109. 
12. Masoudi, A. Strukturelle Phasenanalyse von chemischen Prozessadditiven in der Silikat-Industrie; Springer Fachmedien Wiesbaden: Wiesbaden, Germany, 2019.

13. Masoudi, A. Einfluss der Struktur von Aluminium-Metaphosphaten auf die Chemische Härtung von Kalium-Wasserglas-Bindern. Ph.D. Thesis, University of Koblenz-Landau, Koblenz, Germany, 26 April 2019.

14. Menard, K.P. Dynamic Mechanical Analysis: Practical Introduction, 2nd ed.; Taylor and Francis Group: Boca Raton, FL, USA, 2008. Available online: http://sv.20file.org/up1/608_0.pdf (accessed on 9 January 2020).

15. Hopp, V.; Sax, A.; Helmus, D.; Quirmbach, P. Adaptation of the dynamic mechanical analysis to determine the gel point during the setting of liquid alkali silicates. Int. J. Appl. Ceram. Technol. 2019, 16, 2331-2341. [CrossRef]

16. Hofmann, K.; Glasser, W.G. Cure monitoring of an epoxy-amine system by dynamic mechanical analysis (DMTA). Thermochim. Acta 1990, 166, 169-187. [CrossRef]

17. Kim, S.Y.; Choi, D.G.; Yang, S.M. Rheological analysis of the gelation behavior of tetraethylorthosilane / vinyltriethoxysilane hybrid solutions. Korean J. Chem. Eng. 2002, 19, 190-196. [CrossRef]

18. Gan, H.; Hess, P.C.; Kirkpatrick, J. Phosphorus and boron speciation in $\mathrm{K}_{2} \mathrm{O}-\mathrm{B}_{2} \mathrm{O}_{3}-\mathrm{SiO}_{2}-\mathrm{P}_{2} \mathrm{O}_{5}$ glasses. Geochim. Cosmochim. Acta 1994, 58, 4633-4647. [CrossRef]

19. Brus, J.; Abbrent, S. Advances in 27Al MAS NMR studies of geopolymers. Annu. Rep. NMR Spectrosc. 2016, 88, 79-147.

20. Schulz, M. Festkörper-NMR-Untersuchungen zur Strukturaufklärung mesostrukturierter Aluminiumphosphate. Ph.D. Thesis, Friedrich-Schiller-Universität Jena, Jena, Germany, 4 December 2002.

21. Bleuzen, A.; Barboux-Doeuff, S.; Flaud, P.; Sanchez, C. Rheological study of titanium oxide-based gels. Mater. Res. Bull. 1994, 29, 1223-1232. [CrossRef]

22. Wijnen, P.W.J.G.; Beelen, T.P.M.; Rummens, C.P.J.; van Santen, R.A. Diffusion- and reaction-limited aggregation of aqueous silicate solutions. J. Non-Cryst. Solids 1991, 136, 119-125. [CrossRef]

(C) 2020 by the authors. Licensee MDPI, Basel, Switzerland. This article is an open access article distributed under the terms and conditions of the Creative Commons Attribution (CC BY) license (http://creativecommons.org/licenses/by/4.0/). 